Review Article

\title{
Extraterrestrial Components from Deep Sea Sediments of Indian Ocean
}

\author{
N G RUDRASWAMI* and M SHYAM PRASAD
}

National Institute of Oceanography (Council of Scientific and Industrial Research), Dona Paula, Goa 403 004, India

(Received on 10 April 2016; Accepted on 11 April 2016)

\begin{abstract}
Two different types of extraterrestrial particulate matter collections were undertaken during the last few years - by using magnets encased in dredges that were dragged along the seafloor and by sieving massive quantities of deep sea sediments from which cosmic spherules were subsequently isolated. Detailed investigations on close to 1000 sectioned cosmic spherules revealed the presence of Pt-group nuggets in all the three basic types of cosmic spherules - all of whom had carbonaceous chondritic meteorites as precursors, thus in a way unifying them. Further, Fe-Ni beads in all types of the investigated cosmic spherules further confirmed this finding. Oxygen isotopes of relict-grains in silicate cosmic spherules suggested chondrules from carbonaceous chondrites to be major contributors. In addition, relict chromite grains and dusty olivines observed in several cosmic spherules suggested that at least $3 \%$ of the cosmic material that rains on the earth is sourced from ordinary chondrites. The Australasian microtektites found in the Indian Ocean retained unique microimpact features generated while they were in flight due to inter-particle collisions in the ejecta. This unique phenomenon outlined the importance of the impact process during estimation of cosmic dust fluxes estimated from lunar materials.
\end{abstract}

Keywords: Micrometeorites; Deep Sea Sediments; Microtektites; Flux; Chondrites

\section{Introduction}

Particulate material, having size of tens of micrometer to few millimeters (Love and Brownlee, 1991, 1993; Taylor et al., 2000; Genge et al., 2008) dominate the extraterrestrial material flux of $\sim 30,000$ tonnes/year. Only a small fraction of such material which hits the top of the atmosphere survives the rigors of atmospheric entry, while a majority gets evaporated during entry. Nevertheless, these micrometeorites can be isolated and collected from diverse environments and comprise a vast variety of extraterrestrial materials, perhaps even wider than those that make up the known meteorites (Taylor et al., 1998; Yada et al., 2005). Many micrometeorites have shown chemical, isotopic and trace element characteristics that can be linked to chondrites. Since they comprise of diverse materials, understanding the chemical and isotopic properties of micrometeorites provides significant insights and enhances our understanding of the solar system. Frictional heating during their entry into the Earth's atmosphere alters their texture and chemical compositions, thereby losing information related to their formation and their parent bodies. Understanding the precursors, their thermal history in parent bodies, relation to the meteoritic components such as chondrules, calcium aluminum rich inclusions (CAIs), and their matrix therefore poses an important challenge in the investigation of micrometeorites. Earlier studies of mineralogical and isotopic investigations have linked a majority of the micrometeorites to carbonaceous chondrites (Kurat et al. 1994; Brownlee et al., 1997; Greshake et al. 1998; Rudraswami et al., 2012, 2014). However, there is ambiguity on the specific component of the meteorites of which the particles are a part.

The samples that are size-sorted are classified as mostly Iron, Stony and Glassy type spherules. The S-type are further divided as barred olivine, radial pyroxene spherules, porphyritic olivine, relict grains, Glass spherules or CAT spherules etc. Progressive heating during atmospheric entry gives rises to these different textures; rarely, some of these texture could

*Author for Correspondence: E-mail: rudra@nio.org 
be primary as well. The bulk chemistry of S-type spherules is related to carbonaceous chondrites (Kurat et al., 1994; Beckerling and Bischoff, 1995; Brownlee et al., 1997; Greshake et al., 1998). However, linking these spherules to specific chondritic components such as refractory inclusions or chondrules is very challenging, especially considering that chondrules constitute $\sim 70 \%$ by volume (Brearly and Jones, 1998). I-type spherules comprise of a combination of magnetite and wustite and at times contain a metallic Fe-Ni bead (Blanchard et al., 1980). The Fe-Ni bulk compositions at first appearance indicate that these particles are derived from metal-rich parent bodies, but careful analyses suggest that majority of these spherules have originated from chondritic bodies and could even be individual metal grains in chondritic meteorites (Herzog et al., 1999). The most accepted explanation for the metal-segregation leading to the formation of I-type spherules is that the heating of a carbonaceous silicate particle during atmospheric entry leads to metal segregation due to the pyrolysis and removal of oxygen. Subsequently, silicate-metal partitioning leads to the formation of a $\mathrm{Fe}-\mathrm{Ni}$ bead inside the particle. This bead would be ejected from the immiscible silicate regions due to inertial forces which upon subsequent oxidation produces wustite and magnetite (Brownlee et al., 1983; Genge and Grady, 1998). However, cosmogenic radionuclides studies in I-type spherules suggests that some of them could be pristine bodies which entered as $\mathrm{Fe}-\mathrm{Ni}$ particles (Herzog et al., 1999). The G-type spherules comprise of a dendritic network of magnetites in glass and often show the presence of $\mathrm{Fe}-\mathrm{Ni}$ bead (Blanchard et al., 1980). The precursors for the G-type spherules are not known with clarity yet. They have been suggested to be the end products from metal-rich stony meteorites (Blanchard et al., 1980); an enstatite chondrite (Bates, 1986); or an unknown metal-rich asteroid (Brownlee et al., 1997).

\section{Sample Collection}

There have been several collections of micrometeorites from the stratosphere, Polar Regions and from the low sedimentation areas of the deep sea regions of the world oceans. A first Indian attempt has been made during the 2006-2007 comprising of a massive effort involving magnetic (biased collection) and sieving large quantities of deep sea sediment (unbiased collection) (Fig. 1). The earlier collection in the Indian Ocean started with panel of magnets of more than 1400 Gauss capacity fixed to a dredge which was dragged along the deep seafloor for a large collection of cosmic material. Secondly, the cosmic spherules were also collected from deep sea sediments of the central Indian Ocean, between longitude 74 to $76^{\circ} \mathrm{E}$ and latitude -13 and $-10^{\circ} \mathrm{S}$, at water depths of $\sim 5200 \mathrm{~m}$ that penetrated the seafloor of $\sim 15 \mathrm{~cm}$

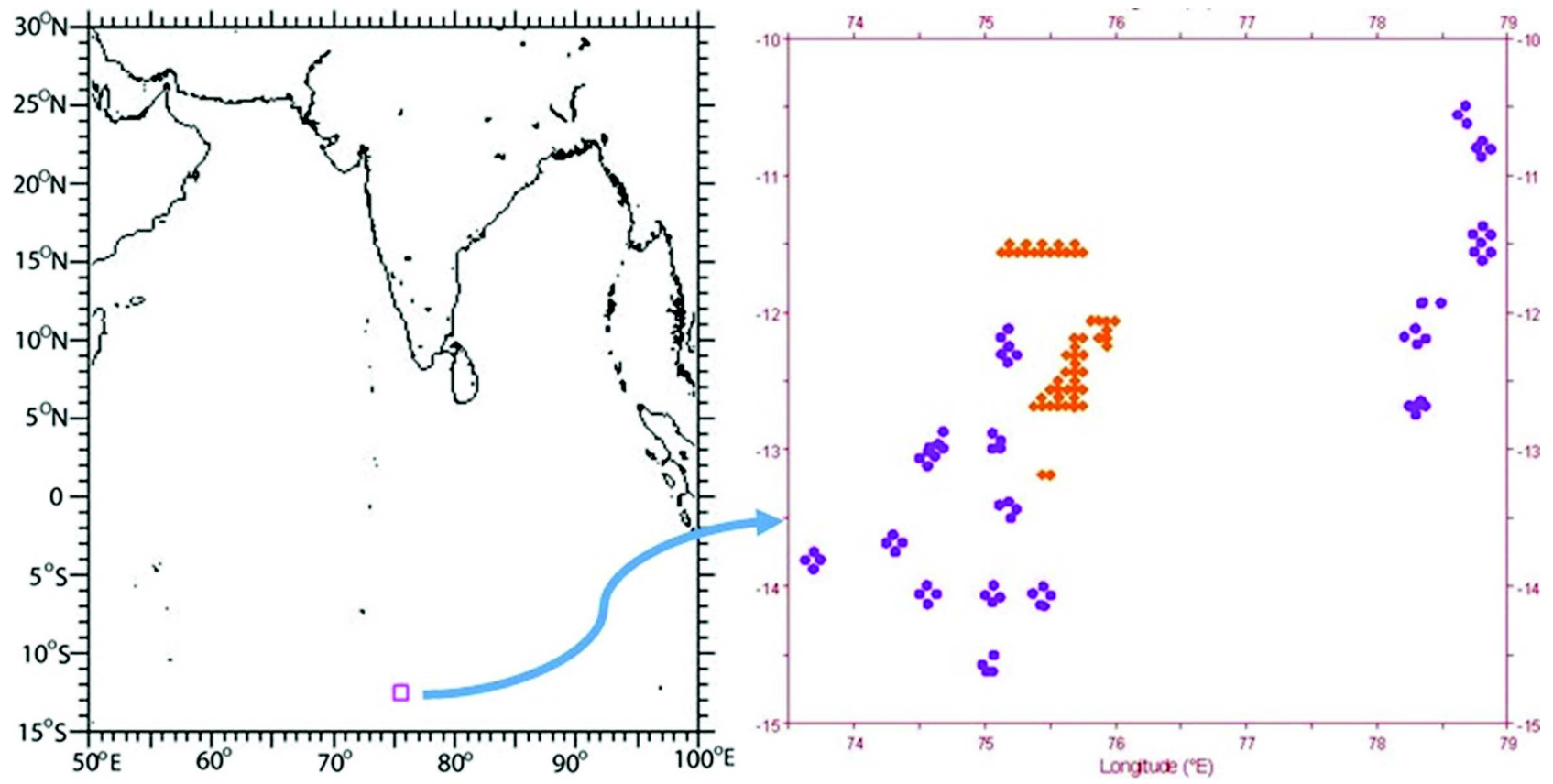

Fig. 1: Map showing Central Indian Ocean from where the deep sea sediments was collected for recovering cosmic spherules 
(Parashar et al., 2010; Rudraswami et al., 2011, 2012, 2014, 2015; Prasad et al., 2013, 2015) (Fig. 2). Close to $\sim 3$ tonnes (wet weight) of sediment were sieved on two different cruises of Akademik Aleksandr Sidorenko (a research vessel chartered by Government of India) from 100 closely-spaced operations. The recovered sediments were sieved using 200 ìm sieve size followed by magnetic separation. Cosmic spherules were handpicked under microscope from the magnetic separates and mounted followed by polishing to expose their internal features (Fig. 3).
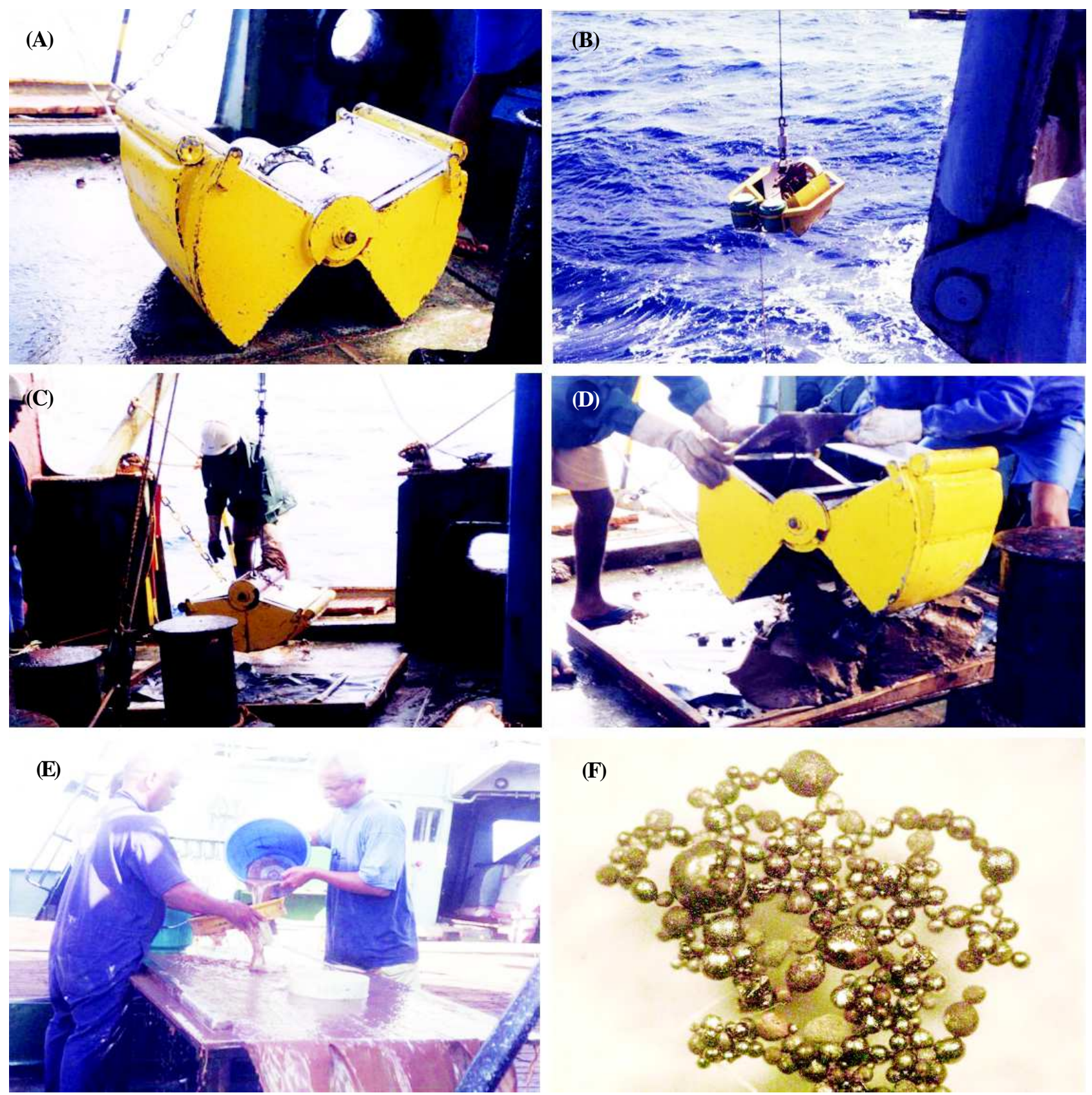

Fig. 2: Grab sample collection during cruises of Akademik Aleksandr Sidorenko: (A) Grab, (B) grab lowered in deepsea, (C) grab picked deep sea sediment brought back to deck, (D) sample unloaded, (E) sample sieving and processing and (F) cosmic spherules under microscope 

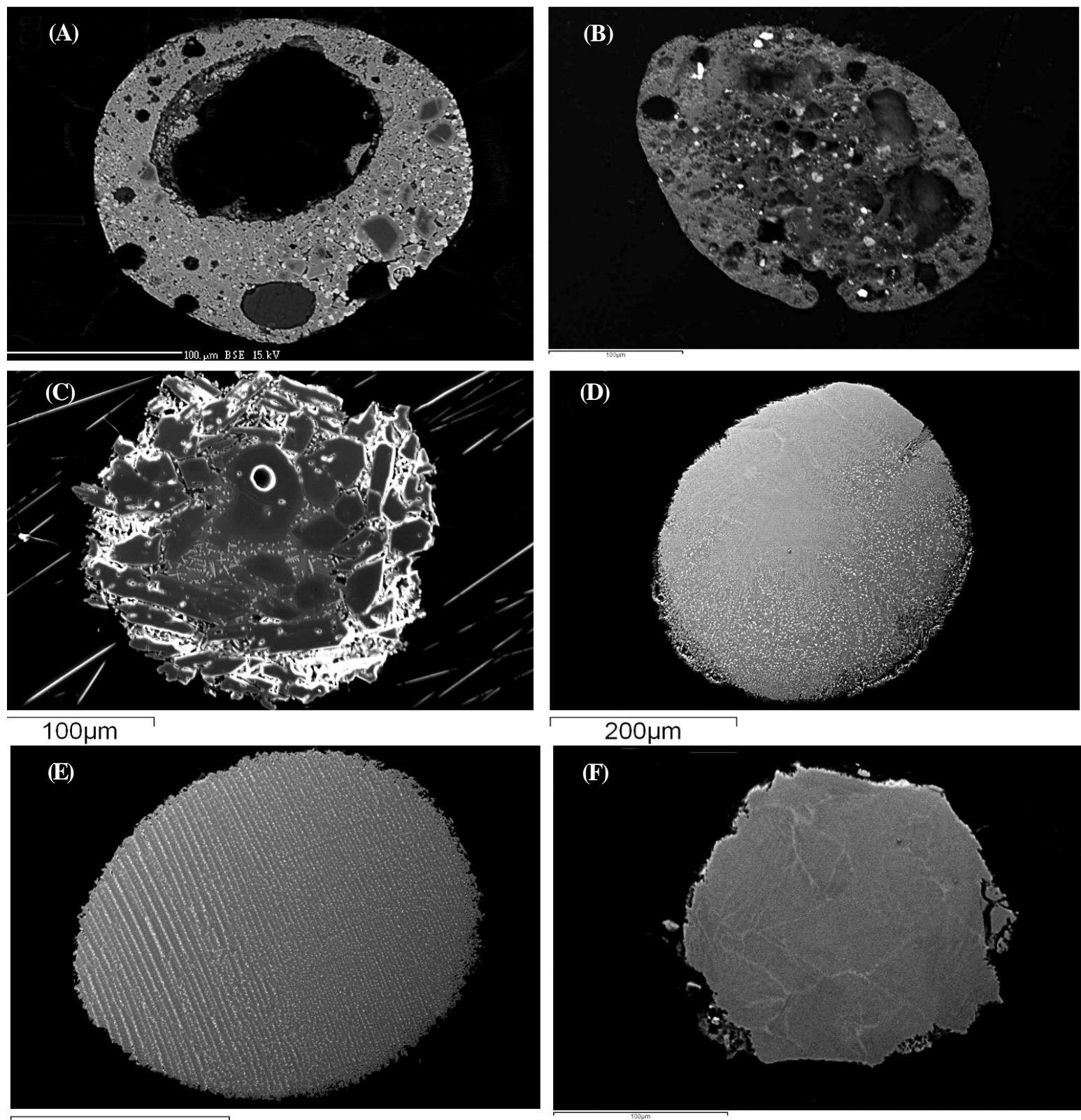

$200 \mu \mathrm{m}$
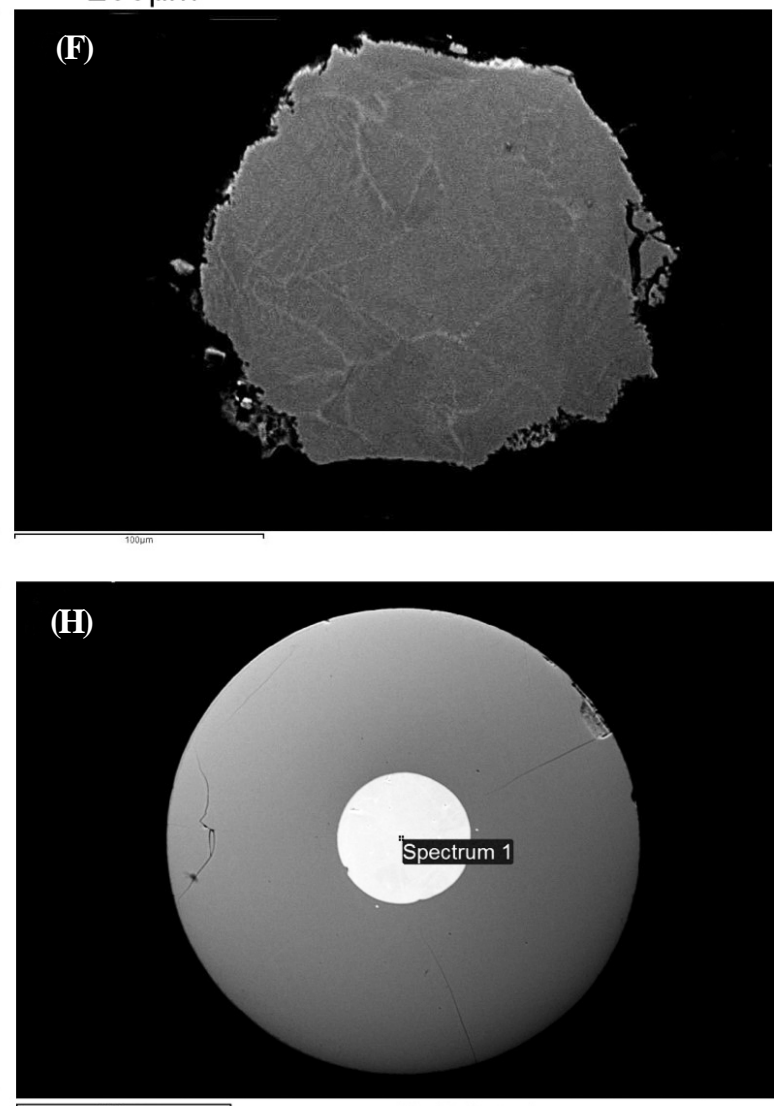

$100 \mu \mathrm{m}$

Electron Image

$100 \mu \mathrm{m}$

Electron Image 1

Fig. 3: Different types of cosmic spherules: (A) relict-grain bearing (zoned olivines), (B) scoriacious (C) porphyritic (D) cryptocrystalline (E) barred, (F) glass, (G) G-type spherule with a Fe-Ni bead and (H) I-type spherule with a Fe-Ni bead 


\section{Discussion}

\section{Platinum Group Element Nuggets in Cosmic Spherules}

The platinum group nuggets (PGNs) of micrometer $(>3 \mu \mathrm{m})$ sizes have been reported earlier in I-type spherules (Brownlee et al., 1984). Rudraswami et al. (2011) examined 175 I-type spherules out of which 13 spherules have shown PGNs among which four nuggets are of $\mu \mathrm{m}$ size. In addition to these, they also discovered nanometer size PGNs. Both the nugget types are common phenomenon in I-type spherules. The large micron sized nuggets are dominated by Ir, $\mathrm{Os}$ and $\mathrm{Ru}$, while the sub-micron sized PGN's are dominated by $\mathrm{Pt}, \mathrm{Rh}$ and $\mathrm{Pd}$. The large size nuggets are usually found one per spherule and are located close to the edge of the spherule. However, there are hundreds of nanometer-sized nuggets that are distributed in the magnetite phases of the spherules. Chemically, the $\mu \mathrm{m}$-sized PGNs shows chondritic Os/ Ir ratios, but are depleted in the volatile PGE $(\mathrm{Pt}, \mathrm{Rh}$, and $\mathrm{Pd}$ ) relative to chondritic ratios. The Palladium is depleted in $\mu \mathrm{m}$ sized nugget while it has been observed in $8 \%$ of sub- $\mu \mathrm{m}$ sized nugget. The refractory PGE Os and Ir are absent in the sub- $\mu \mathrm{m}$ sized nuggets. These observations suggest that the PGE were fractionated into the IPGE (Ir, Os, Ru) and PPGE (Pt, Rh, Pd) efficiently during the short span (seconds) of atmospheric entry. The fractionation of PGE has implications on the understanding of the Earth's core formation. This process also has implications on the identification of projectiles based on PGE measurements in meteorite impact ejecta. A large fraction of the cosmic spherules that enter the earth are completely vaporized leaving these PGE nuggets released in the troposphere, suggesting that that some of these nuggets could also be a part of the meteoric smoke observed in the troposphere.

After the initial discovery PGE nuggets in I-type spherules by Brownlee et al. (1984), such nuggets were reported very rarely in any other spherule. Rudraswami et al. (2014) made a massive effort in mounting and sequential polishing of 992 cosmic spherules collected by raking the deep seafloor with magnets. The spherules were ground sequentially every 10 micrometers, polished and observed in the SEM for potential PGE nuggets. This enormous effort yielded the finding of 54 Refractory Metal Nuggets
(RMN), out of which 23, 26, and 5 nuggets are from $23 \mathrm{I}-, 21 \mathrm{~S}$ - and 5 G-type cosmic spherules, respectively (Rudraswami et al., 2014). For the first time, RMNs were reported from all the three basic types of cosmic spherules. This is so far the largest number of nuggets observed in any study of cosmic spherules. The RMNs in all the three spherule types follow metal segregation patterns which suggested their formation during atmospheric entry due to heating and oxidation of chondritic materials. I-type spherules show volatilization sequence in refractory metal elements from a chondritic source. The relatively volatile RMEs in I-type spherules are depleted or distributed in numerous smaller nanometersized nuggets. Whereas in G-type spherules, RMNs show closer relationship to CI chondrites and do not show any large volatile depletion. S-type spherules RMNs were reported to be enriched in the volatile and refractory PGEs (Rudraswami et al., 2014). The enrichment patterns and elemental ratios are close to CI composition for refractory elements, suggesting a common formation process. Pulse heating during atmospheric entry of the particle seems to be a competent procedure for PGE segregation into nuggets.

\section{Glass Cosmic Spherules}

Observation of 36 glass spherules that has smooth and spherical external features led to the understanding of the fractionation, fragmentation and ablation process of the large sized spherules during atmospheric entry (Rudraswami et al., 2012). Externally, many glass spherules contain either a Sirich glass or Fe-Ni rich cap over their surfaces. The atmospheric entry of the spherules have preserved the relict grain even while the temperature experienced by them is $\sim 1700^{\circ} \mathrm{C}$ required for vaporization of volatile elements like $\mathrm{Fe}$ and resulting in enrichment of $\mathrm{Si}, \mathrm{Ca}$ and $\mathrm{Mg}$. The Calculations with a chemical ablation model (CABMOD) suggest an entry velocity of $\sim 11-16 \mathrm{~km} / \mathrm{sec}$ to attain the temperature required for glass spherule formation. These condition indicate the micrometeoroid undergoes a mass loss of $\sim 20 \%$. An increase in velocity changes the chemical composition of the particles or have Fe-Ni bead. However, further heating of the spherules does not have a Fe-Ni bead, but possesses a platinum group nugget at the front end. This is the only glass spherules reported by us that has micrometer nugget in them. 
The nugget has a diameter of $\sim 3 \mu \mathrm{m}$ and contains all the PGE, although some volatile PGE's are depleted. The PGE in the nugget seems to have a trend that is different other PGE of I-type spherules, and seems to be related to Calcium Aluminum rich Inclusions (CAIs), the earliest solar system objects to be formed. Further, the trace element geochemistry of the glass spherules suggested enrichment of 1.6 times the CI chondrite values, suggesting that atmospheric entry heating has not led to significant change in these refractory elements and seems to have great resemblance to carbonaceous chondrites. The Chemical ablation model (CABMOD) was used to determine the entry condition which will produce these spherules and estimate the mass loss. The model suggested us to restrict the entry velocity from 11 to $16 \mathrm{~km} / \mathrm{s}$ and suggest an ablation $20 \%$.

\section{Flux of Cosmic Spherules}

Nearly 3 tons of sediments collected from more than 100 locations of Indian Ocean were sieved. This is perhaps the largest collection effort so far. To understand the flux of the micrometeorites that survive the atmospheric entry and also to gain an insight into the micrometeoroid complex over long residence times, Prasad et al. (2013) investigated cosmic spherules isolated from ten such grab samples (i.e., from $\sim 300 \mathrm{~kg}$ of deep sea sediment). The grab usually penetrates the seafloor up to $\sim 15 \mathrm{~cm}$ and covers an area of $50 \times 50 \mathrm{~cm}$ making the equivalent carpet area of 2.5 square meters. Nearly $45 \mathrm{Kg}$ of sediment is picked grab during each operation. The samples were sieved onboard using $200 \mu \mathrm{m}$ mesh and the magnetic material from the sieved sediment. Spherules were hand-picked under the binocular microscope from this material. Understanding the terrestrial age of the cosmic spherules is key to calculate the flux of the micrometeorites. Prasad et al. (2013) also took three cores from this part of the Indian Ocean. From these cores, they isolated Australasian microtektites which have an age of 0.77 Ma (Kunz et al., 1995; Izett and Obradovich, 1992). This event was used as a chronostratigraphic marker and the rates of sedimentation were calculated. Based on the peak abundance of micrometeorites, they suggested a terrestrial age of $0-50,000$ years for the cosmic spherules recovered from these sediments. Further, based on the number of cosmic spherules abundance and sedimentation rates, the flux of cosmic spherules was estimated to be $\sim 160$ tons per annum (Prasad et al., 2013). This is the flux of cosmic materials that have survived the harsh conditions of the ocean floor. The actual flux may be much higher as many spherules could have been destroyed in the sieving process, error in the diameter measurement of the cosmic spherules and sedimentation rates, apart from etching in the seawater that affect such an assessment. However, this is the best estimate for greater than $200 \mu \mathrm{m}$ size spherules that survived the atmospheric entry. The unbiased collection done on these ten grab samples have the various textural features similar to those from polar collections (Taylor et al., 2000), except for a slightly higher percentage of I-type (5.2\%) and G-type (3.3\%) spherules in Antarctic micrometeorites collection, except for the I-type and G-type which have slightly higher percentage of 5.2 and $3.3 \%$ respectively. This is because I-type and G-type spherules have offer greater resistance to etching thereby increasing the percent contribution compared to other spherules. The elemental ratios for all these spherules analyzed are close to $\mathrm{CI}$ and $\mathrm{CM}$ carbonaceous chondrites, suggesting these meteorites as the precursors for a majority of particulate cosmic materials on the earth.

\section{Fe-Ni Beads in Cosmic Spherules}

The Fe-Ni bead formation in the cosmic spherules is an atmospheric entry phenomenon. The beads are commonly observed in all types of cosmic spherules due to heating during entry that gives rise to reduction within the particle where the metal segregates due to siderophile attraction and is later released in the atmosphere due to inertial forces (Brownlee et al., 1984, 1997). The I-type spherules are thus generated by the release of metal particles which, during atmospheric entry, have oxidized leading to the formation of wustite and magnetite. Beads are found in all cosmic spherules, and the PGE contained in the beads could lead to understanding of the fundamental aspect of the origin of all cosmic spherules. Rudraswami et al. (2014) investigated 2000 cosmic spherules in a search for $\mathrm{Fe}-\mathrm{Ni}$ beads, out of which $55 \mathrm{Fe}-\mathrm{Ni}$ bead containing spherules from all the basic types, i.e., I-, S-, G-types cosmic spherules were analyzed for the refractory metal elements such as $\mathrm{Re}, \mathrm{Os}, \mathrm{W}, \mathrm{Ir}, \mathrm{Ru}, \mathrm{Mo}, \mathrm{Pt}, \mathrm{Rh}$ and Pd. The PGE content of these beads confirmed the classical understanding of the process of bead formation during atmospheric 
entry as suggested by Brownlee et al. (1984). More importantly, the CI and Os normalized data suggested that the precursors for all the three different types of cosmic spherules have a source which is close to CI chondritic - thus providing a unifying argument for all cosmic spherules. Furthermore, the PGE content of the beads in I-type spherules as compared to G- and S-type spherules were much higher indicating greater efficiency of segregation of PGE in metal and also due to variation in oxidation potential between the $\mathrm{Fe}-$ $\mathrm{Ni}$ and the PGE. The study supported metal rich carbonaceous chondrites as precursors for bead formation in the cosmic spherules.

\section{Oxygen Isotope in Relict Olivine of Cosmic Spherules}

Oxygen isotopes are useful to understand the origin and the processes undergone by the cosmic materials during the early solar nebula. Relict olivine grains enclosed in the cosmic spherules were chosen for this study as they have survived the heating during atmospheric entry. Rudraswami et al. (2015) selected twelve cosmic spherules from $\sim 1500$ that contained Mg-rich relict grains with sizes greater than $20 \mu \mathrm{m}$. A total of 31 oxygen isotope analyses were done using ion microprobe. The data lie close to the CCAM (Carbonaceous Chondrite Anhydrous Mineral) line, with $\Delta^{17} \mathrm{O}$ ranging from -5 to $0 \%$. The data overlay oxygen isotopic compositions of chondrules from $\mathrm{CV}$, $\mathrm{CK}, \mathrm{CR}$ and $\mathrm{CM}$ carbonaceous chondrites which indicated that chondrules from carbonaceous chondrites are precursors of relict grains in cosmic spherules. Further, the chemical compositions of olivine were found to be comparable to olivines from chondrules of carbonaceous chondrites. Three cosmic spherules had relict grains that were ${ }^{16} \mathrm{O}$-rich $\left(\Delta^{17} \mathrm{O}\right.$ -21.9 to $-18.7 \%$ ), similar to oxygen isotopic compositions observed in refractory inclusions, amoeboid olivine aggregates (AOAs), and some porphyritic chondrules from carbonaceous chondrites. These grains appeared to have formed in the inner solar nebula. Three olivine grains from two cosmic spherules that had $\delta^{18} \mathrm{O}$ values $>+20 \%$ o were understood as mixing with stratospheric oxygen during atmospheric entry.

\section{Ordinary Chondritic Eelation}

Prasad et el. (2015) investigated 481 micrometeorites that were separated from $\sim 300 \mathrm{~kg}$ of deep sea sediment, out of which 15 spherules distinctly retained signatures of their parent bodies. Seven spherules contained chromites that had chemical features resembling sub-groups of ordinary chondrites. The remaining spherules showed dusty olivines as relic grains. Dusty olivine chondrules have been found dominantly in unequilibrated ordinary chondrites and were suggested to have formed due to solid state reduction of fayalite (Rambaldi and wasson, 1982). Two of these spherules reported by Prasad et al. (2015) appeared to be chondrules from an unequilibrated ordinary chondrite and another spherule was identified as a Porphyritic Olivine Pyroxene (POP) chondrule. The bulk chemical composition of the cosmic spherules indicate an ordinary chondritic source for all the spherules. The chromite bearing spherules are less than a few percent of the total collection. They have retained their composition during the earth's atmospheric entry. These micrometeorites also provide evidence of contribution from ordinary chondritic sources to the fluxes on the earth. It is likely that there could be a higher number of particles with ordinary chondritic origin, but alteration during atmospheric entry does not allow us to estimate their exact input.

\section{Microtektites}

A small group has been working on meteorite impact ejecta recovered from sediment cores from the Central Indian Ocean. More specifically, the investigations were focused on the tektite producing Australasian impact which took place over $0.77 \mathrm{Ma}$ ago. Since reporting the discovery of a flanged australite button in the Indian Ocean (Prasad and Rao, 1990), this group has made several discoveries. The more recent among them being the observation of impact generated microcraters on the microtektites and tektites of the Australasian tektite strewn field (Prasad and Sudhakar, 1996, 1998; Prasad and Khedekar, 2003). The aspect of microimpacts has perhaps been the most extensively investigated aspect of lunar research. Prasad and his group had earlier suggested that the similarities between the ubiquitously found microcraters on lunar materials and those on the Australasian microtektites suggest that the micrometeoroid flux on the lunar surface had been overestimated by several investigators.

Intensive investigation into this phenomenon on 4600 Australasian microtektites from 11 sediment 


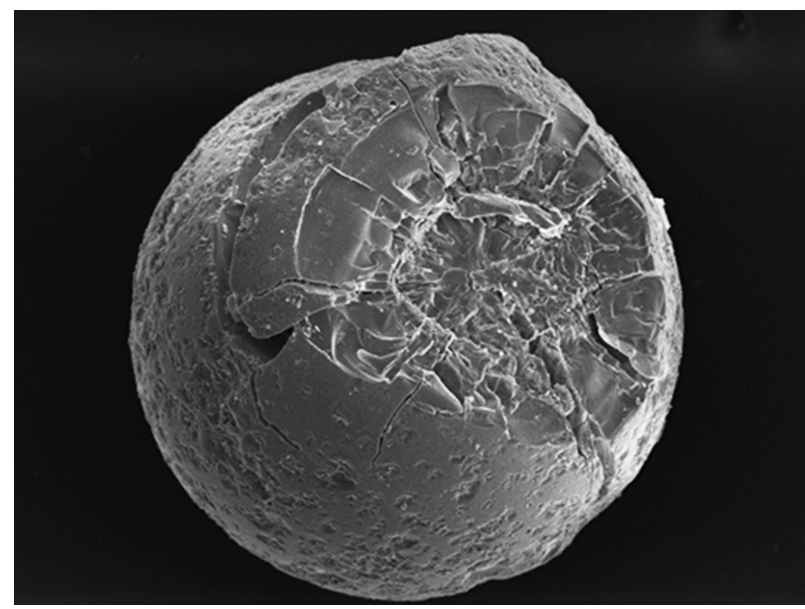

Fig. 4: SEM image of a hypervelocity microimpact crater on an Australasian microtektite. The collision took place while the particle was in flight in the ejecta (the microtektite has a diameter of $\sim 200 \mu \mathrm{m}$ )

cores along an $\mathrm{N}-\mathrm{S}$ transect in the Central Indian Ocean have been carried out optically for microimpact features on their surfaces. Detailed scanning electron microscope examination of 68 microtektites along this transect shows 4091 such features. These samples are located between approximate distances of 3900 $5000 \mathrm{~km}$ from the suggested impact site in Indochina and therefore constitute distal ejecta. The morphology

\section{References}

Bates B A (1986) The elemental composition of stony extraterrestrial particles from the ocean floor $\mathrm{PhD}$ thesis University of Washington $199 \mathrm{pp}$

Beckerling W and Bischoff A (1995) Occurrence and composition of relict minerals in micrometeorites from Greenland and Antarctica-implications for their origins Planet Space Sci 43 435-449

Blanchard M B, Brownlee D E, Bunch T E, Hodge P W and Kyte F T (1980) Meteoroid ablation spheres from deep-sea sediments Earth Planet Sci Lett 46 178-190

Brearley A J and Jones R H (1998) Chondritic meteorites. In Planetary Materials (ed. J J Papike) Reviews in Mineralogy 36 3-1 to 3-398

Brownlee D E, Bates B A and Wheelock M M (1984) Extraterrestrial platinum group nuggets in deep-sea sediments Nature 309 693-695

Brownlee D E, Bates B and Schramm L (1997) The elemental composition of stony cosmic spherules Meteorit Planet of the microimpacts seems to show distinct variations with distance from the source crater. The total number of microcraters on each microtektite decreases drastically from North to South indicating systematic decrease in the spatial density of the ejecta, and decrease in collisional activity between microtektites with distance from the proposed source crater location. Closer to the proposed source crater location, the microcraters are predominantly small, pit bearing with radial and concentric cracks, suggestive of violent interparticle collisions. The scenario is reverse farther from the source crater with smaller numbers of impacted microtektites due to increased dispersion of the ejecta and the microcraters are large and shallow, implying gentle collisions with larger particles. These observations provide systematic ground truth for the processes that have taken place as the ejecta of a large oblique impact which generated the Australasian tektite strewn field is emplaced. The microimpacts appear to have occurred during the descent of the ejecta and their intensity and number density decrease as a function of the spatial density of the ejecta at any given place and with distance from the source region. These features could help understand processes that take place during ejecta emplacement on planets with substantial atmosphere such as Mars and Venus.

\section{Sci 32 157-175}

Brownlee D E, Bates B A and Beauchamp R H (1983) Meteor ablation spheres as chondrule analogs. In Chondrules and Their Origins, ed. E.A. King, pp. 10-25, Houston: Lunar Planet Inst

Genge M J and Grady M M (1998) Melted micrometeorites from Antarctic ice with evidence for the separation of immiscible Fe-Ni-S liquids during entry heating Meteorit Planet Sci 33 425-434

Genge M J, Engrand C, Gounelle M and Taylor S (2008) The classification of micrometeorites Meteorit Planet Sci $\mathbf{4 3}$ 497-515

Greshake A, Klock W, Arndt P, Maetz M, Flynn G J, Bajt S and Bischoff A (1998) Heating experiments simulating atmospheric entry heating of micrometeorites: Clues to their parent body sources Meteor Planet Sci 33 267-290

Herzog G F, Xue S, Hall G S, Nyquist L E, Shih C Y, Wiesmann $\mathrm{H}$ and Brownlee D E (1999) Isotopic and elemental composition of iron, nickel, and chromium in type I deep- 
sea spherules: implications for origin and composition of the parent micrometeoroids Geochim Cosmochim Acta 63 1443-1457

Izett, G A and J D Obradovich (1992) Laser-fusion 40Ar/39Ar ages of Australasian tektites Lunar Planet Sci XXIII abstract 593

Kunz J, K Bollinger, E K Jessberger and D Storzer (1995) Ages of Australasian tektites Lunar Planet Sci XXVI abstract 809

Kurat G, Koeberl C, Presper T, Brandstatter F and Maurette M (1994) Petrology and geochemistry of Antarctic micrometeorites Geochim Cosmochim Acta 58 3879-3904

Love S G and Brownlee D E (1991) Heating and thermal transformation of micrometeoroids entering the Earth's atmosphere Icarus 89 26-43

Love S G and Brownlee D E (1993) A direct measurement of the terrestrial mass accretion rate of cosmic dust Science $\mathbf{2 6 2}$ 550-553

Parashar K, M Shyam Prasad and S S S Chauhan (2010) Investigations on a Large Collection of Cosmic Dust From the Central Indian Ocean Earth Moon Planets (2010) 107 197-217 DOI 10.1007/s11038-010-9362-3

Prasad M S, Rudraswami N G and Panda D K (2013) Micrometeorite flux on earth during the last $\sim 50,000$ years J Geophy Res 118 2381-2399

Prasad M S, Sandip Kumar R O Y and Avinash Gupta (2010) Changes in abundance and nature of microimpact craters on the surfaces of Australasian microtektites with distance from the proposed source crater location Meteoritics \& Planetary Science 45 990-1006

Prasad M S and M Sudhakar (1996) Impact microcraters on an Australasian microtektite Meteoritics and Planetary Science 31 46-49

Prasad M S and M Sudhakar (1998) Microimpact phenomena on Australasian microtektites : implications for ejecta plume characteristics and lunar surface processes Meteoritics and Planetary Science 33 1271-1279

Prasad M S and Rao P S (1990) Tektites far and wide Nature 347 340
Prasad M S M, N G Rudraswami, A D Araujo, E V S S K Babu and T Vijaya Kumar (2015) Ordinary chondritic micrometeorites from the Indian Ocean Meteoritics and Planetary Science 50 1013-1031

Rambaldi R and Wasson J T (1982) Fine, nickel-poor Fe-Ni grains in the olivine of unequilibrated ordinary chondrites Geochimica et Cosmochimica Acta 46 929-939

Rudraswami N G, M Shyam Prasad, E V S S K Babu, T Vijaya Kumar, W Feng and J M C Plane (2012) Fractionation and fragmentation of glass cosmic spherules during atmospheric entry Geochimica et Cosmochimica Acta 99 110-127

Rudraswami N G, Parashar K and Shyam Prasad M (2011) Micrometer and nanometer size platinum group nuggets in micrometeorites from the deep sea sediments of Indian Ocean Meteorit Planet Sci 46 470-491

Rudraswami N G, M Shyam Prasad, E V S S K Babu and T Vijaya Kumar (2014a) Chemistry and petrology of Fe-Ni beads from different types of cosmic spherules: Implication for precursors Geochimica et Cosmochimica Acta 145 139158

Rudraswami N G, M Shyam Prasad, J M C Plane, T Berg, W Feng and S Balgar (2014b) Refractory Metal nuggets in different types of cosmic spherules Geochimica et Cosmochimica Acta 131 247-266

Rudraswami N G, M Shyam Prasad, K Nagashima and R H Jones (2015) Oxygen isotopic composition of relict olivine grains in cosmic spherules: Links to chondrules from carbonaceous chondrites Geochimica et Cosmochimica Acta $16453-70$

Taylor S, Lever J H and Harvey R P (2000) Numbers, types and compositions of an unbiased collection of cosmic spherules Meteorit Planet Sci 35 651-666

Taylor S, Lever J H and Harvey R P (1998) Accretion rate of cosmic spherules measured at the South Pole Nature 392 899-903

Yada T, Nakamura T, Noguchi T, Matsumoto N, Kusakabe M, Hiyagon H, Ushikubo T, Sugiura N, Kojima H and Takaoka $\mathrm{N}$ (2005) Oxygen isotopic and chemical compositions of cosmic spherules collected from the Antarctic ice sheet: implications for their precursor materials Geochim Cosmochim Acta 69 5789-5804. 